\title{
LOS PRIMEROS NOTICIARIOS CINEMATOGRÁFICOS DEL "NO-DO" EN JAÉN (1943-1944). Un análisis de la fiesta y propaganda de la dictadura de Francisco Franco
}

\author{
José Antonio MESA BELTRÁN \\ Universidad de Jaén \\ jamb0007@red.ujaen.es
}

THE FIRST CINEMATOGRAPHIC NEWS OF THE “NO-DO” IN JAÉN (1943-1944). An analysis of the party and propaganda of the dictatorship of Francisco Franco

Resumen: Con motivo del $75^{\circ}$ aniversario de la exhibición pública en los cines (4 de enero de 1943) de los noticiarios y documentales cinematográficos "NO-DO", en nuestro caso relacionado con la provincia de Jaén. Planteamos el análisis de aquellos noticiarios comprendidos en los dos primeros años del nacimiento de la productora española. Puesto que dichos programas cinematográficos asientan los modelos propagandísticos del régimen durante 30 años en el cine. El estudio nos permite revisar las relaciones entre el cine y la iconografía presentada por el régimen que tiene como base ideológica los preceptos del "movimiento nacional". Bajo dicha forma de pensamiento, con un férreo control por el organismo estatal dictatorial, se convierte en una herramienta clave en la base del discurso de progreso económico, acción social y política del régimen franquista.

Abstract: On the occasion of the 75th anniversary of the public exhibition in cinemas (January 4, 1943) of the newsreels and documentaries "NO-DO", in our case related to the province of Jaen. We propose the analysis of those news programs included in the first two years of the birth of the Spanish producer company. These cinematographic programs establish the advertisement models of the regime for 30 years in the cinema. The study allows us to review the relationship between the cinema and the iconography presented by the dictatorship, which has as its ideological base the precepts of the "national movement". Under this form of thought, with a hard control by the dictatorial state, the newsreels becomes a key tool at the base of the discourse of economic progress, social and political action of the Franco regime.

Palabras clave: NO-DO. Filmoteca Española. Dictadura. Fiesta. Jaén. Cine Spanish Film Archive. Dictatorship. Festival. Jaen. Cinema 


\section{Introducción}

Los espectadores e investigadores que se acercan por primera vez a la producción cinematográfica de los noticiarios y documentales "NO-DO", tienen que tener claro tres aspectos esenciales por los que se conciben y se caracterizan los elementos fílmicos de la productora española. Principalmente, en sus noticiarios que son: el espectáculo -cine-, la información -periodismo- y la propaganda -ideología- (Paz Rebollo; Sánchez Alarcón, 1999: 22).

Dichas características, sobre todo la propaganda de carácter educativo y legitimadora, le viene a la productora de cine por su carácter de herramienta al servicio del régimen para convencer -dentro de la nación y en el extranjero-, sobre el progreso llevado a cabo por la política del "caudillaje y la falange" en materia de reconstrucción ideológica, social y económica del nuevo "Estado Unitario" (Hernández Robledo, 2003: 189-194).

En la actualidad los noticiarios "NO-DO" son documentos históricos factibles de ser analizados desde diferentes perspectivas sociales, históricas, artísticas, etc. Por ejemplo, de esto mismo dan cuenta algunos artículos entre los que destacamos aquellos relacionados con las provincias de Andalucía. Estos son los casos de Córdoba (Jurado Arroyo, 2003; Mendoza Yusta, 2015-2016: 339-349), Málaga (Ventajas Dote, 2006 a; 2006 b: 187-221), Granada (Ventajas Dote, 2005:127-172), Huelva (Navarrete-Galiano, 2003) o Jaén (Roll Grande, 2011:85-90; Sánchez Martínez; Jódar Mena, 2017:2245-2254).

En el resto de provincias andaluzas los diferentes profesionales paulatinamente trabajan en identificar las localizaciones que aparecen en los noticiarios o investigan las imágenes de "NO-DO" con otros aspectos más complejos. Estos últimos, alejados de los trabajos de catalogación y localización, tienen como objetivo avanzar hacia una mejor compresión del archivo cinematográfico a través de estudios multidisciplinares como ocurre en el caso de la provincia de Jaén (Jódar Mena, 2016: 156-157) y su geografía (Sánchez Martínez; Jódar Mena, 2017:2245-2254).

Nuestro objetivo en el análisis de las imágenes de los noticiarios "NO-DO” en Jaén, trata de rastrear una parte de nuestra historia inmediata junto con su necesaria revisión a través de otras fuentes. Una revisión del material fílmico que pretendemos como una serie de "fotografías animadas" (Tranche; Sánchez-Biosca, 2006: 20) que permitan reconocer los diversos elementos de la historia oficial y no oficial de la provincia de Jaén.

La producción cinematográfica de "NO-DO" con la provincia de Jaén la constituyen cerca de 67 noticiarios -algunos reaprovechan imágenes ya emitidas- junto con 6 documentales en blanco y negro, 11 documentales en color y la revista "Imágenes" con un total de 17 producciones.

Antes de la cinematografía de "NO-DO" la provincia ya es protagonista de dos producciones fílmicas caracterizadas por su componente de cine documental (Camarero Rioja, 2014: 6-7; 16) y que adelantan algunos aspectos de "NO-DO".

El primero es la película Fumigación de los olivos por medio del gas cianhídrico $(1914)^{1}$, dirigida por el ingeniero agrónomo Leandro Navarro y rodada por Francisco Oliver operador de la casa Pathé Frères de Barcelona. El film destaca por su carácter de cine educativo (Camarero Rioja, 2013: 13-59).

Dicha película, relacionada con algunos noticiarios de "NO-DO", busca enseñarnos el progreso industrial del olivar y el interés del Estado en la protección de la cosecha de la aceituna - el noticiario 535 A (1953) rodado en Villanueva del Arzobispo es un buen ejemplo-.

El segundo documento es un magnífico antecedente de lo que son las futuras proyecciones sobre las visitas del dictador Francisco Franco y sus ministros en la provincia giennense

1 [Consulta: 18/03/2018] https://api.picturepipe.net/api/3.0/playouttoken/4f529d493d404f58adf32692b88348 9b/play 
a través de los noticiarios. El film se titula: A voyage of H.M. King Alphonso XIII through the province of Jaen (Andalusia) (1926)2.

La película, realizada por una productora inglesa, capta algunos de los monumentos de las ciudades de Baeza y Úbeda, además de los trabajos relacionados con el olivar y su modernización. Destacamos dentro de la relación con "NO-DO", las imágenes de Alfonso XIII acompañado de su cortejo militar y civil junto con aquellas secuencias que nos presentan la espontaneidad de acciones. Un ejemplo de estos momentos es la secuencia de Alfonso XIII sentado en el banquete, el cual ignora el discurso del dictador Miguel Primo de Rivera.

En definitiva, la película tiene nexos comunes con "NO-DO" pero a la vez tiene enormes diferencias en la forma de tratar a los protagonistas, sobre todo, la figura del dictador de Miguel Primo de Rivera - casi cómica-.

Aunque ambas películas brevemente descritas tienen como contexto la provincia de Jaén, apenas se mostraron en los cinematógrafos públicos de las ciudades o su exhibición tiene como destino el extranjero. Por ello, consideramos que ambas filmaciones constituyen una especie de "antecedente mítico" a otras producciones cinematográficas con escenario en la provincia, con algunas características comunes pero a la vez con muchas y evidentes diferencias que quedan por analizar en futuros trabajos.

Incluso unos meses antes de la emisión de "NO-DO" conocemos los datos de la solicitud de una productora madrileña a la Diputación Provincial para el rodaje de un documental sobre la provincia ${ }^{3}$.

"Dada cuenta de una atenta comunicación de la Casa productora de películas cinematográficas Hispano Documental y enterada la Comisión gestora de la gran importancia que para los intereses provinciales puede suponer la realización de un documental que refleje la vida, usos y costumbres de nuestra provincia, se acordó prestar a la "Hispano Documental" cuanta colaboración y apoyo moral precise de esta Corporación y subvencionarla en la cuantía que en su día se fije, visto el guión o bosquejo de la película que se proyecta y el metraje de la misma".

Pero la institución provincial rechaza el proyecto para la película el 5 de junio de $1942^{4}$.

"Examinado el proyecto de guión de lo que podrá ser la película documental de esta capital, con longitud aproximada de 300 metros y duración de diez minutos que remite la Casa de Madrid "Documental Español" y de conformidad con el dictamen de la Ponencia de Hacienda, se acordó no acceder de momento a lo solicitado por la Empresa Editora, por no alcanzar dicha película los deseos de esta Corporación para propaganda de la riqueza de esta provincia y carecer de consignación apropiada en el vigente presupuesto".

Sin embargo, a través del diario Jaén tenemos el conocimiento del rodaje de la película en el mes de enero de $1943^{5}$ con el título de "La tierra del olivo" (Imagen 1).

2 [Consulta: 18/03/2018] https://api.picturepipe.net/api/3.0/playouttoken/886d9ab1eaa945a786ce0a22499f31 de/play

3 Archivo Histórico de la Diputación Provincial de Jaén (AHDPJ). Actas celebradas por la comisión gestora de la excma. Diputación Provincial desde el 25 de febrero hasta el 7 de diciembre de 1942. Signatura: A-174. 25 de marzo de 1942. Folio $27 \mathrm{r}$.

4 AHDPJ. Actas celebradas por la comisión gestora de la excma. Diputación Provincial desde el 25 de febrero hasta el 7 de diciembre de 1942. Signatura: A-174. 5 de junio de 1942. Folio 76 v. -77 r.

5 V. y M.: "Cómo se hace la primera película sobre Jaén. Se llamará «la tierra del olivo» y medirá 300 metros", Jaén. Diario de Falange española tradicionalista y de las J.O.N.S. Núm. 558. 16 de enero de 1943, p. 3. 


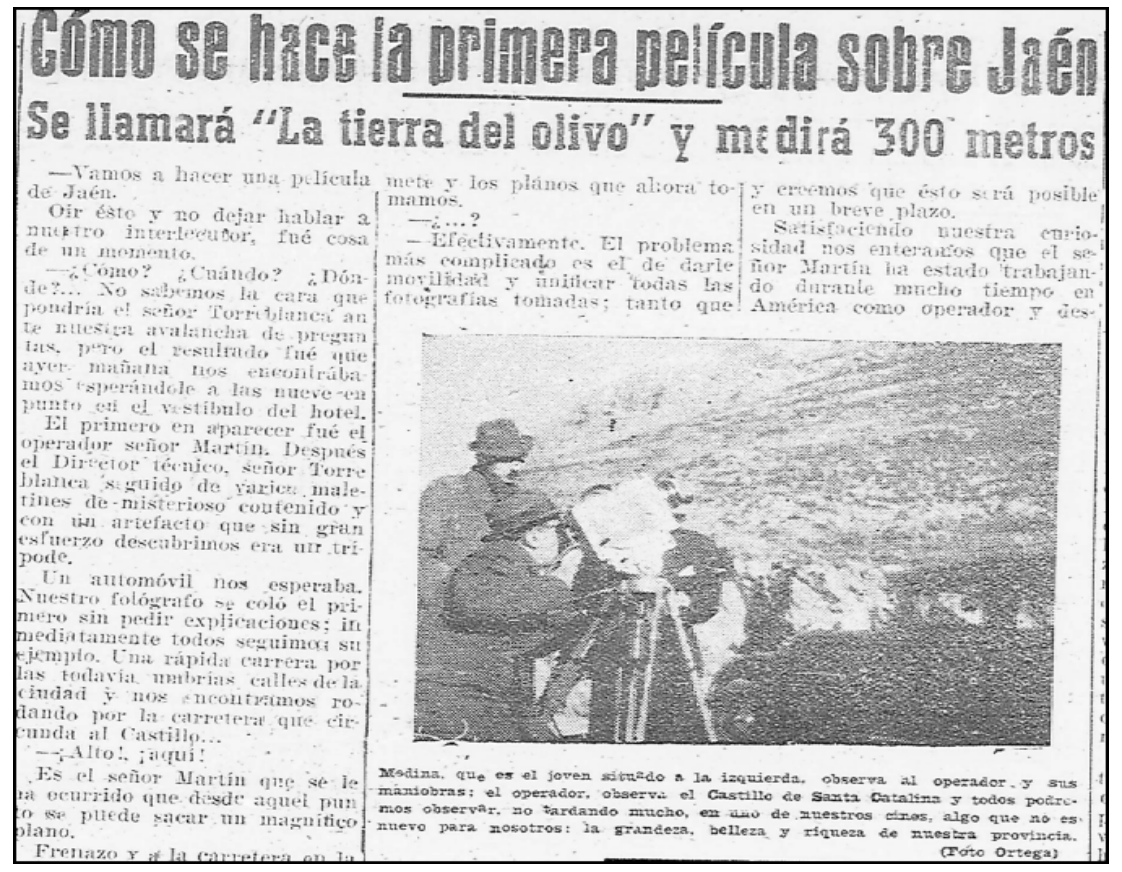

Imagen 1. Reportaje en el diario Jaén sobre el documental “La tierra del Olivo” (1943).

El rodaje tiene como objetivo capturar instantáneas sobre monumentos de la capital como el castillo y el templo catedralicio, las plazas de San Francisco y las Batallas, o las obras realizadas en el ensanche, todo bajo el hilo argumental del "ciclo de elaboración y producción de la aceituna". En el fondo fotográfico de la familia Ortega -custodiado en el Instituto de Estudios Giennenses- conserva seis fotografías del operador con la cámara y los reporteros giennenses. En ese momento, el de la captura de las imágenes por el operador de cine, es descrito de la siguiente manera en el periódico ${ }^{6}$.

Seguidamente son adosados al trípode un pequeño motor de enorme precisión y un reóstato que inmediatamente se conectan con una batería. Cálculos de luz, distancia, etc.: enfoque, un cigarrillo, la fotografía de la claqueta en la que se lee "JAÉN-Pla 1" y se va a comenzar a rodar.

Se oye unos momentos el apagado ruido del motor y el Castillo de Santa Catalina ha quedado impresionado para el documental "La tierra del olivo".

El equipo de rodaje de "Documentales Nacionales" continúa el 21 de enero su periplo por la capital ${ }^{7}$. El grupo organizado por el operador Martín y el director-técnico Torreblanca -que trabaja en ocasiones para "NO-DO"-, ruedan en este día dentro de la catedral. El interés de los cineastas en la catedral estriba en captar el acto de la adoración del Santo Rostro. En dicha manifestación religiosa participan los miembros del concejo municipal -alcalde y concejales-, delegados de otras instituciones y el cabildo catedralicio.

Por último, el diario nos informa sobre la idea de exhibir el documental -una vez montado- en los cines de la ciudad a finales del mes de marzo ${ }^{8}$. Además, el reportero nos describe

\footnotetext{
6 Ibídem.
}

7 Anónimo.: "Ayer se filmó la piadosa adoración al Santo Rostro", Jaén. Diario de Falange española tradicionalista y de las J.O.N.S. Núm. 563. 22 de enero de 1943, p. 2.

8 Anónimo.: "El documental «La Tierra del Olivo» ultimado. Se proyectará en Jaén en el mes de marzo". Jaén. Diario de Falange española tradicionalista y de las J.O.N.S. Núm. 566. 26 de enero de 1943, p. 2. 
las últimas tomas del rodaje de la película en el lugar de la Senda de los Huertos en Jaén capital. Con bailes regionales interpretados por la Sección Femenina y el Frente de Juventudes, vestidos sus miembros con los trajes folclóricos de pastira y chirri. En la actualidad no sabemos si se conserva la película.

No nos podemos olvidar de la contextualización del presente trabajo en los años de 1943-1944 en Jaén y en España. Un período que se caracteriza por las iniciativas económicas del régimen franquista basadas en la austeridad y autarquía, que se traduce en el total control de los racionamientos de productos básicos - con un gran mercado negro-. A esto se le une el estancamiento de los derechos sociales con una represión violenta emanada de las instituciones oficiales y de las clases sociales afectas al "Nuevo Estado" (Cobo Romero, 1994: 509-510).

Por ello, la visita de Francisco Franco a Jaén en 1943 tiene carácter de apoteosis triunfal, ya que es la primera vez que visita la provincia. Pero la relación directa del dictador con la provincia ya se había iniciado antes. En concreto, durante los meses de febrero y marzo de 1940. Esto se debe al acto de la devolución de la reliquia del Santo Rostro -en el palacio de El Pardo- recuperada en un barrio del extrarradio de París. Dicha circunstancia la aprovecha el régimen para su propaganda (Colorado Castellary, 2018: 117-123), desde titulares locales como "El Caudillo ha cumplido su promesa de devolver a Jaén la Santa Faz", hasta en medios nacionales en el que aparece el discurso tópico del dictador sobre los ideales de "cruzada y patria"10.

\section{EI noticiario 21 B. La llegada del dictador Francisco Franco a la capital}

Este noticiario constituye el colofón del periplo por toda Andalucía del nuevo "Jefe del Estado" tras cuatro años en el poder. Por todo ello, el dictador imparte unos siete discursos diferentes en cada provincia - en Jaén el tema es "la doctrina de la Falange Nacional" (Gutiérrez Navas, 2003:33-34)-, con un doble objetivo. El primero para celebrar la victoria militar y el ascenso al gobierno de la nación del general militar. Y el segundo, el régimen trata de mostrarnos una imagen de adhesión popular inquebrantable al nuevo gobierno como forma de protesta al aislamiento internacional (Rodríguez Mateos, 2005:183).

El noticiario recogido en el número 21 B lleva el título, según el programa de mano, de: "El Triunfal viaje del Caudillo. Sevilla, Granada, Jaén y Madrid tributa a Su Excelencia el Jefe del Estado un impresionante homenaje de adhesión y fervor". La secuencia relacionada con Jaén tiene apenas una duración de unos 30 segundos, con la llegada del dictador y los actos realizados en su honor.

El reportaje cinematográfico con las imágenes de Jaén capital lo podemos dividir en tres actos; una primera con la llegada del dictador en coche y las muestras populares de bienvenida en la plaza de santa María; el segundo acto consiste en la concentración en el campo de fútbol de la Victoria de una gran multitud relacionada con representaciones de la falange tradicional y de la JONS; y el tercer acto, y el más carismático cinematográficamente, es el desfile por las calles de la ciudad con los participantes en la concentración falangista y la presidencia del dictador en el cortejo -en un estrado en solitario-.

En el noticiario podemos observar arquitecturas efímeras, banderas, inscripciones laudatorias del nombre del dictador, mujeres vestidas de folclore, etc. Toda una amalgama de símbolos destinados a la exaltación y ennoblecimiento de la figura del dictador que le permiten crear una imagen de marca con infinidad de símbolos y connotaciones (Durante Asensio, 2014: 75).

9 Anónimo.: "El Caudillo ha cumplido su promesa de devolver a Jaén la Santa Faz", Ideal en Jaén. Granada. Año IX. Núm. 2334. 18 de febrero de 1940. s/f.

10 Anónimo.: "La Santa Faz, en Madrid", ABC (Edición de la mañana). Madrid. Año XXXIII. Núm. 10630. 19 de marzo de 1940, pp. 11-12. 


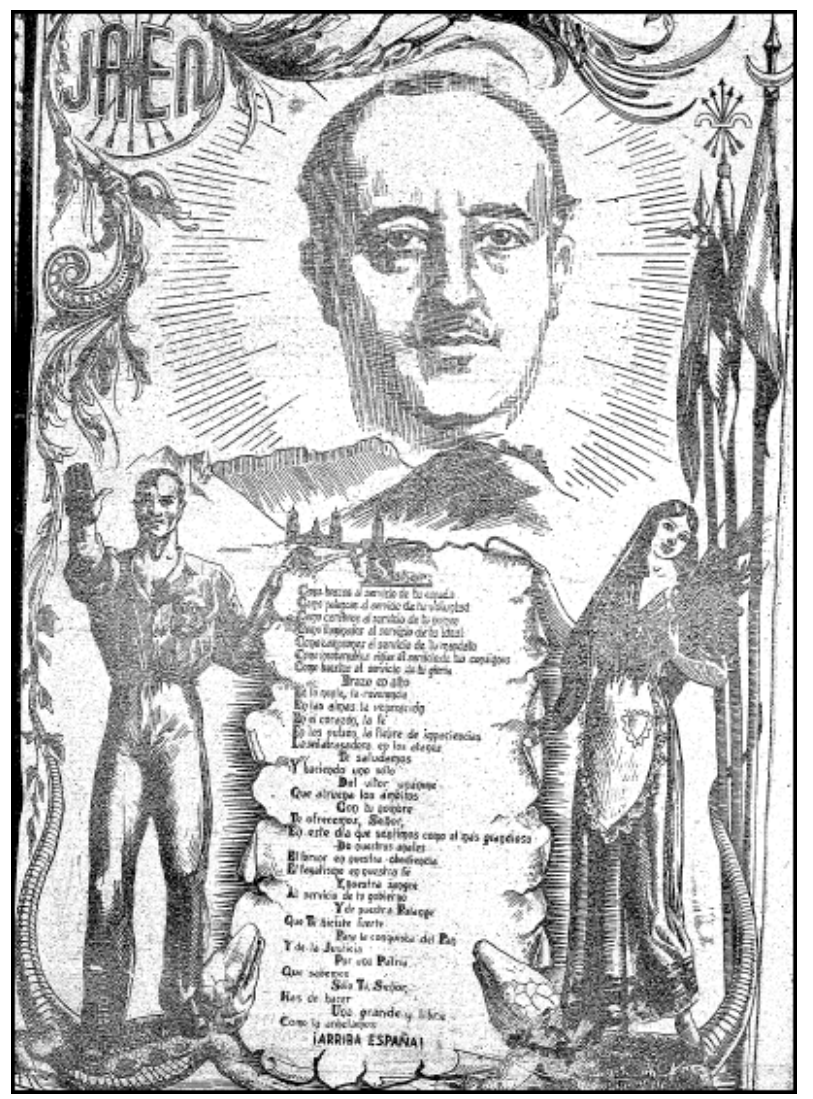

\section{Imagen 2. Grabado conmemorativo de la visita de Franco (1943).}

Muchas veces en esa infinidad de símbolos se entremezclan ciertas connotaciones locales o, mejor dicho, apropiaciones que evidencian una búsqueda iconográfica para asimilar la figura del dictador con la ciudad que visita. Esto lo podemos observar en un grabado publicado en el periódico "Jaén. Diario de Falange española tradicionalista y de las J.O.N.S"11.

Dicho dibujo realizado por el pintor y cartelista Manuel Serrano Cuesta ${ }^{12}$, tiene como objetivo la exaltación del dictador junto con los signos de la falange, como son el yugo y las flechas, o el uniforme del hombre con el saludo fascista. Nos llama la atención que las figuras del hombre y la mujer-vestida de pastira- aparecen sobre dos reptiles. Estos tienen connotaciones locales con la ciudad de Jaén, ya que se asimilan a la leyenda del lagarto (Imagen 2).

Es decir, en el grabado el artista no duda en emplear aquellos aspectos de identidad iconográfica de la ciudad de Jaén y adscribirlos a la imagen heroica del dictador. Aunque el cartelista se asegura de no caer en el error, puesto que la imagen del lagarto también hace alusión al refrán popular de referencias negativas "así revientes como el lagarto de Jaén".

En relación con el noticiario de 1943 y el periódico, la película nos muestra aquellos acontecimientos más multitudinarios relacionados con los momentos más álgidos de la falange en la visita del dictador. Pero en el periódico aparecen recogidos otros actos desglosados en la siguiente tabla ${ }^{13}$.

11 SERRANO CUESTA, M.: [Grabado] Jaén. Diario de Falange española tradicionalista y de las J.O.N.S. Jaén. Núm. 655.9 de mayo de 1943, p. 9.

12 Sobre la formación y obra del pintor ver: Almansa Moreno; Martín Robles, 2016: 553.

13 Confeccionado a partir de los datos del periódico: Jaén. Diario de Falange española tradicionalista y de las 
12. 25 h. Entrada de la ciudad del dictador; recibimiento por los niños de las Escuelas Nacionales y una bandera del Frente de Juventudes en la carretera de Granada.

Recorrido por la ciudad en vehículo descapotable; Itinerario: Avenida de Madrid, Calle de Baeza, Avenida del Generalísimo (Paseo de la Estación), Roldán y Marín, Plaza de José Antonio (Constitución), Bernabé Soriano (Suelta de 200 palomas blancas) y Plaza de Santa María (NODO).

Lonja de la catedral de Jaén (NO-DO): recibimiento por autoridades civiles de Jaén, eclesiásticas y un batallón Ciclista; Interior catedral: “Te Deum” y Visita cripta de El Sagrario.

Concentración Falangista y de productores en el campo municipal de fútbol de la Victoria. Junto con 20 bandas de música (NO-DO).

Visita a la zona del Ensanche: Obras de las Viviendas de las Protegidas de los Sindicatos; Parque y jardines de la Victoria

Desfile de las secciones de Falange y Productores (NO-DO).

15.00 h. Comida de gala en la Diputación Provincial. Banda Municipal dirigida por Emilio Cebrián y coros de canto y baile de la sección femenina.

Visitas y regalos honoríficos al dictador: diploma de los ancianos de Torredonjimeno; álbum con dibujos de niños de las escuelas; medalla de oro del Santo Rostro, etc.

Inauguración de la Guardería de Auxilio Social; en el salón de actos visita del dictador de una exposición de planos con los proyectos arquitectónicos realizados desde el 1 de abril de 1939.

\section{Tabla 1. Resumen de Actos Oficiales del dictador Francisco Franco en Jaén capital descritos en los periódicos durante el 11 de mayo de 1943.}

El narrador, apoyado por el guión, es el que permite adscribir las imágenes del noticiario con el carácter de baño de masas populares que apoyan al dictador alegremente, junto con la fidelidad total partido único de la falange.

Las formulas léxicas empleadas en el discurso por el narrador busca crear un mensaje de adhesión al gobierno del dictador. Este código lo consigue transmitir el locutor a través del entusiasmo visto en las otras ciudades visitadas por el militar en su recorrido por Andalucía. Con frases como "iguales muestras de entusiasmo que las restantes ciudades andaluzas de su recorrido".

Sobre la arquitectura efímera que nos muestra el noticiario cinematográfico, sobre todo, el arco triunfal al inicio de las secuencias de Jaén capital. En el periódico se le describe de la siguiente manera ${ }^{14}$ :

"El Arco Monumental de la calle Bernabé Soriano-. En la encrucijada que hace la calle Bernabé Soriano con la plaza del Deán Mazas, ha sido levantado por el Ayuntamiento un arco monumental de diez metros de altura que ha costado 20.000 pesetas, y que ha sido proyectado por el arquitecto señor Sánchez. Es una magnifica muestra de grandiosidad y tiene muy marcadas reminiscencias de la arquitectura monumental alemana, asemejándose a la puerta de Brandemburgo de la Unter den Linden berlinense. Consta de cuatro grandes sobre los que cae un templete estriado en sentido horizontal. Ha sido construido en madera sobre la que va una capa de cañizo recubierto de yeso

J.O.N.S. Números: 655-656-657; 9-12 de mayo de 1943. En negrita aparece la palabra: (NO-DO) corresponde a los actos exhibidos en las secuencias del noticiario.

14 Anónimo.: "A las once de la mañana llegará el Caudillo", Jaén. Diario de Falange española tradicionalista y de las J.O.N.S. Núm. 656. 11 de mayo de 1943, p. 5. 


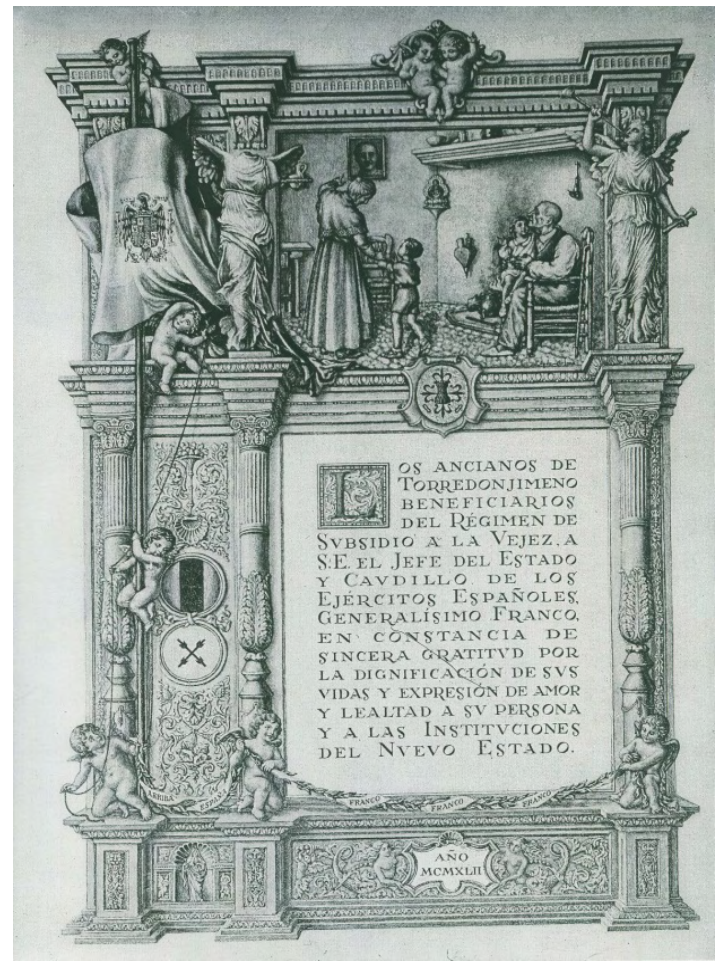

Imagen 3. Diploma que los ancianos de Torredonjimeno dedican a Franco (1943).

\begin{abstract}
y un enfoscado tirolés. Ha sido preciso clavar diez grandes vigas de madera y otras dieciséis de menor diámetro. Llevará dispuestos el escudo de la ciudad y el de España y los emblemas del Movimiento, en los paños que cierran dos de los huecos laterales. En la fachada que da a la calle Bernabé Soriano figura la siguiente inscripción: "El Ayuntamiento de Jaén saluda al Caudillo", y ambos lados la triple cartela de Franco, Franco, Franco".
\end{abstract}

No es el único elemento de este tipo de arquitectura efímera que se describe en el periódico, otro elemento que destaca el periodista es la tribuna creada en la calle Roldán y Marín -última secuencia del noticiario de Franco en Jaén-. El objetivo es presentar estas obras como alardes de la técnica española y del buen gusto puestos al servicio del programa festivo del dictador y la falange. A la vez que se trata de copiar formulas extranjeras como queda dicho por el periodista en el arco conmemorativo, incluso lo compara con la icónica puerta de Brandemburgo de Berlín.

Tal alarde festivo es sufragado por las instituciones públicas del momento (Gobernación Civil, Ayuntamiento, etc.) como atestigua la autorización de la comisión gestora de la Diputación Provincial de Jaén a la presidencia para los gastos necesarios por la visita del dictador, ya sea para "reparaciones, limpieza, pintura, agasajos, etcétera"15.

De estos agasajos - el más caro una medalla de oro del Santo Rostro-, conservamos la fotografía del diploma entregado al dictador por los beneficiados por el subsidio de la vejez de Torredonjimeno ${ }^{16}$. Del diploma destaca la escena realizada por el pintor José López

15 AHDPJ. Signatura: A-178. Actas celebradas desde el 15 de abril de 1943 al 11 de septiembre de 1943.30 de abril de 1943. Folio $6 \mathrm{r}$.

16 Instituto de Estudios Giennenses (IEG). Signatura: A-647-1/3. [Diploma que los ancianos de Torredonjimeno 
Arjona $^{17}$. El cual sitúa en un interior doméstico a una pareja de ancianos de clase social obrera que enseñan a sus nietos el retrato del dictador colgado en la pared. Todo el diploma aparece enmarcado con una arquitectura renacentista junto con los símbolos de la falange y el escudo heráldico del municipio de origen de los beneficiarios del subsidio (Imagen 3).

Sobre los actos de la falange que aparecen en el noticiario $21 \mathrm{~B}$, nos encontramos con aquellos tópicos descritos por Tranche y Sánchez-Biosca (2006: 218-219). Es decir, el "papel decorativo" del partido único en el baño de masas del dictador en el estadio municipal de la Victoria, que le permite exhibir una imagen de lealtad inquebrantable entre el dictador y el partido único - que a su vez organiza al pueblo y lo militariza-.

Esto se manifiesta en el desfile triunfal con el que cierra el noticiario, una forma de instrumentalización social, del que las cámaras de los operarios de "NO-DO" destacan la juventud de los participantes y su asignación a equipos gimnásticos, junto con la presencia multitudinaria de la sociedad en el acontecimiento, con el dictador como último y principal protagonista aislado del resto de la muchedumbre.

Una fiesta contralada hasta el más mínimo detalle, como nos lo demuestra la tarjeta de invitación expedida por el ayuntamiento de Jaén al teniente José Escobedo ${ }^{18}$. Junto con el menú del almuerzo de honor ofrecido al dictador en la Diputación, con el programa del concierto musical para amenizar el acto ${ }^{19}$.

Casi un mes después de la visita del dictador, en el diario Jaén del 5 de junio de 1943, aparece un pequeño artículo sobre la exhibición del noticiario 21 B en los cines de la capi$\mathrm{tal}^{20}$.

Con ser siempre interesante el noticiario español "No-Do", lo es aún más por traernos la visita del Caudillo a Jaén, que para nosotros es lo más interesante que contiene. Se ve al Generalísimo Franco en la tribuna monumental presenciando la gran concentración provincial de falangistas y productores y, además, el magnífico desfile, así como su paso por el gigantesco arco de la Carrera, aclamado siempre por la multitud pletórica de júbilo. El público que presenciaba esta proyección la acogió con multitud de aplausos.

El artículo nos permite comprender el alcance de los noticiarios cinematográficos entre la población. Ya que el periodista nos muestra una opinión positiva de la exhibición del noticiario, puesto que la imagen pública del dictador Francisco Franco se presenta reforzada gracias a las herramientas visuales utilizadas por el régimen como la "monumentalidad de las arquitecturas efímeras y la asistencia de multitud de personas".

Todo esto afecta a unos espectadores fáciles de impresionar -con altas tasas de analfabetismo-, unido a que el cine es el mayor medio con más penetración social por su carácter de entretenimiento, frente a otros medios como la prensa escrita o la radio (Rodríguez Mateos, 2008: 32). Por ello, no es de extrañar la positividad de los espectadores ante la reiteración de tales símbolos y mensajes propagandísticos junto a la censura del libre pensamiento.

\section{El reaprovechamiento de imágenes del noticiario 21 B en 1944}

La carencia de película virgen en estos años (posguerra española y II Guerra Mundial) junto a la propia temporalidad de "NO-DO" en conmemoraciones propias y del régimen

dedican a Franco] [Material gráfico].

17 Sobre la formación y obra del pintor ver: Almansa Moreno; Martín Robles, 2016: 305-306.

18 IEG. Signatura: FOL-JAE-11357. Título: Tarjeta e Invitación Personal e Intransferible a Favor del Teniente Escobedo para los Actos Organizados con Motivo de la Visita a Esta Capital de S.E. el Generalísimo Franco. 1943.

19 IEG. Signatura: FOL-JAE-11368. Título: Almuerzo en Honor de Su Excelencia el Jefe del Estado y Caudillo de España con Motivo de Su Visita a Jaén.

20 Anónimo.: "El «NO-DO» número 21 estrenado en los cines de la ciudad, nos trae la visita del Caudillo a Jaén”, Jaén. Diario de Falange española tradicionalista y de las J.O.N.S. Núm. 678. 5 de junio de 1943, p. 7. 
(Tranche; Sánchez-Biosca, 2006: 291-293). Provoca que el equipo de montaje reutilice los fragmentos de noticias, ya rodadas, o de aquellas secuencias eliminadas de la exhibición en los cines.

En este contexto nos encontramos un par de secuencias descontextualizadas del noticiario 21 B, de la visita de Franco a Jaén en el año 1943, y que no aparecieron en los cines de este año. Esto se debe a la necesidad de ajustar los tiempos del reportaje a las normas de exhibición del noticiario en el cine o a la previa censura. Los noticiarios de 1944 en el que aparecen las secuencias, son:

- Not. 53 B. Un año de NO-DO. Versión en imágenes de 1943. Minuto: 2.593.02. Fecha de exhibición en los cines: 03/01/1944.

- Not. 59 B. ¡Españoles! El Caudillo que ganó la guerra mantiene nuestra estricta neutralidad. Minuto: 9.33-9.37. Fecha de exhibición en los cines: 14/02/1944.

Ambos reportajes cinematográficos exhiben entre 4 a 5 segundos el mismo acto de la entrada del dictador Francisco Franco a la lonja de la catedral de Jaén. Pero en ambos existen diferencias que nos proponemos describir para cada noticiario. Este análisis nos permite obtener una mejor comprensión de la imagen propuesta para su exhibición y atracción del público. Además, nos ayuda a conocer la adaptabilidad de las secuencias de Jaén en el discurso total de los diferentes reportajes con el que los montadores, según las necesidades de la propaganda del régimen, tratan de transmitirnos un determinado mensaje.

\section{El noticiario 53 B. Un año de "NO-DO": análisis del discurso y la imagen}

Los fotogramas que nos exhibe este noticiario es un repaso de variedades sobre todos los acontecimientos recogidos por las cámaras de "NO-DO" en el año 1943, con motivo de su primer aniversario. Entre los objetivos de la empresa cinematográfica, destaca según el narrador, el de "recoger en nuestras imágenes toda la viveza de la actualidad poniendo el cine al servicio de la historia.". Con reportajes sobre manifestaciones artísticas, II Guerra Mundial, festejos populares, deportes, temas del protectorado marroquí o los actos oficiales del Estado dictatorial.

Es en este último contexto en el que se sitúan las secuencias de Jaén, con un discurso relacionado con las muestras populares de afecto que recibe el dictador en las ciudades que visita.

En los fotogramas podemos ver al dictador con una sonrisa y saludando a las personas que lo rodean en su entrada a la lonja de la catedral. Mientras que el fondo de la acción geográfica es la plaza de Santa María con la arquitectura del palacio episcopal y las rejas de la lonja del templo catedralicio.

La importancia de estas imágenes estriba en que nos presentan el cortejo de personas más cercanas a la intimidad del militar, ya que en el noticiario $21 \mathrm{~B}$ siempre aparece aislado del resto de personas. Destaca entre ellas la imagen de Carmen Polo, esposa del dictador, tocada con sombrero de lazo, y el resto de la comitiva lo componen altos cargos gubernamentales de la casa militar y civil del dictador.

En definitiva, suponemos que la imagen no es empleada en el noticiario de 1943 debido a razones de tiempo de montaje y a que muestra al dictador sonriente y acompañado de personas -sin verse la multitud-.

La idea principal de representar al dictador, en el noticiario de 1944, consiste en mostrarlo como una figura reverente de cortesía y adulación, a la vez que se convierte en alegoría del entusiasmo de todos los españoles por la unidad conseguida. 


\subsection{El noticiario 59 B. La paz de Franco: análisis del discurso y la imagen}

Aunque en este reportaje aparece la misma acción que hemos descrito en el apartado anterior, el del dictador en su acceso al templo catedralicio. Nos encontramos algunas diferencias, entre ellas, una primera es el discurso del narrador.

En este caso, el discurso - claramente político- está enmarcado por la idea de neutralidad y el de no participación en la II Guerra Mundial. Esto se debe a las presiones y victorias militares de los Aliados frente a las potencias del Eje.

Para evitar que España se quede aislada internacionalmente por sus tentaciones pro-Eje, en el noticiario se justifica la paz conseguida a raíz de la guerra civil, explicada como "guerra de liberación o cruzada", por el pragmatismo del dictador y la necesidad de paz. Toda esta propaganda es la que afecta a las imágenes de Jaén, las cuales son aprovechadas por el narrador para solicitar la "total adhesión de los españoles" para mantener la paz.

Sobre la descripción de las imágenes, las principales diferencias con los fotogramas del anterior noticiario - $53 \mathrm{~B}$ - se deben a dos detalles. Uno es que podemos ver el mosaico de flores con un escudo heráldico y una palabra escrita en el suelo por el que va a pisar el dictador. Es decir, nos permite conocer los símbolos por los que se articula la teatralidad de la dictadura.

Otra diferencia es que podemos observar el público que vitorea al dictador con más detenimiento. Sobre todo, el grupo de mujeres vestidas con el traje folclórico de pastira que arrojan flores al dictador a modo de bienvenida, y que forman parte del ideario ritual festivo con el que el régimen y el dictador revisten sus visitas triunfales (casos de Sevilla y Granada).

\section{El Noticiario 74 A, un noticiario perdido}

Gran parte del archivo cinematográfico de "NO-DO" está en buen estado de conservación y lo podemos visionar en la web de la Filmoteca Nacional ${ }^{21}$. Sin embargo, los largos años del desinterés por este material, junto a los escasos medios físicos para conservar los rollos tienen como consecuencia que desaparezca un pequeño porcentaje del material.

Del noticiario 74 A conservamos tres minutos de rodaje digitalizado en la web. Esto nos obliga a buscar otras vías para conocer el resto del material que configura el metraje relacionado con Jaén o una primera localización de este rodaje. Para ello, tenemos que acudir a dos fuentes documentales textuales.

El primer documento es el programa de mano que lo encontramos digitalizado en PDF junto al noticiario cinematográfico exhibido en la página web de la Filmoteca Nacional ${ }^{22}$. Este documento contiene una simple sinopsis del material proyectado con los títulos de los reportajes. En el caso de nuestro interés: "Vida Nacional. El Ministro Secretario general del Partido y el de Trabajo visitan Jaén y Linares".

El segundo documento, que nos permite reconstruir las escenas que debe de recoger el reportaje de Jaén, es el guión cinematográfico ${ }^{23}$.

45 m. VIDA NACIONAL. El Ministro Secretario del Partido y el de Trabajo visitan Jaén y Linares.

El Ministro Secretario General del Movimiento camarada Arrese y el de Trabajo camarada Girón, llegan a Jaén para imponer la Medalla de la Vieja Guardia a ochocientos falangistas de aquella provincia.

21 [Consulta: 29/03/2018] http://www.rtve.es/alacarta/videos/noticiarios-nodo/ 22 [Consulta: 29/03/2018] http://www.rtve.es/filmoteca/no-do/not-74/1468170/

23 Agradecemos a Manuel Jódar Mena la información y gestiones para poder consultar dicho documento en la Biblioteca de la Filmoteca Nacional (Madrid). También a los trabajadores y encargados de su custodia en la Filmoteca. 
Ante la Cruz de los Caídos se celebra una solemne misa.

Después del acto religioso, se procede a la imposición de condecoraciones.

15.000 camaradas de las Milicias del Movimiento y Frente de Juventudes y Milicias de Trabajo después de la concentración desfilan ante la tribuna de las autoridades.

Los Ministros se trasladan a Linares donde se verifica una gran concentración de mineros en número superior a 10.000. Esta gran multitud asiste a la imposición de la Medalla de la Minería al Ministro de Trabajo como homenaje de gratitud por las mejoras sociales conseguidas.

Como podemos observar a través del guión, el acto se enmarca dentro de las acciones propagandísticas llevadas a cabo por la falange. Un mensaje con un alto contenido propagandístico y político a favor de los intereses del régimen, que seguramente se incrementa por la falta de análisis de las imágenes.

Destaca en el guión la referencia a un grupo social que forma parte de la historia no oficial del régimen. Nos referimos a la gran concentración de mineros del distrito de La Carolina-Linares. Es a través de este grupo social por el que los reporteros y los ministros franquistas aprovechan para exhibir la imagen de buenas relaciones entre la falange y una de las clases sociales más conflictivas y activas contra el fascismo durante la guerra civil. Convertidos dichos mineros en estos años en un ejemplo de adhesión y armonía económica y social.

La falta de estas imágenes las podemos suplir en parte con la consulta de los actos en los periódicos de la ciudad. En la siguiente tabla recogemos todos los actos llevados a cabo por los ministros franquistas el 14 y 15 de mayo de 1944 en Jaén capital (Imagen 4) y Linares ${ }^{24}$.

Tabla 2. Actos llevados a cabo por los ministros del movimiento y del trabajo en Jaén capital y Linares el 14 y 15 de mayo de 1944.

\section{Domingo, 14 de mayo de 1944. Jaén capital}

8.30 h. Recibimiento de los ministros en la estación de ferrocarril

9.00 h. En el Cementerio católico, imposición del aspa de plata en el féretro del teniente de la División Azul, José Escobedo

9.30 h. Descanso en el Gobierno Civil (Diputación)

10. 30 h. Visita al templo catedralicio; adoración del Santo Rostro y visita a la Cripta.

11.15 h. En la Alameda. Misa Solemne y de campaña ante la cruz de los caídos (NO-DO).

12. 00 h. En la Alameda. Imposición de 800 medallas a la Vieja Guardia y otras condecoraciones a personas afectas al partido único (NO-DO).

13.30 h. Visita a la casas ultrabaratas del Egido de Belén

14.30 h. Desfile. Tribuna de los ministros en la calle Bernabé Soriano (NO-DO).

16.00 h. Almuerzo en el Balneario de Jabalcuz

18.30 h. Entrega de 96 Viviendas Protegidas a los beneficiarios y visita a las obras del Ensanche: Casa de la falange y previsión, etc.

20. 00 h. Salida para el Albergue de turismo de Bailén.

24 Confeccionado a partir de los datos de los periódicos: Jaén. Diario de Falange española tradicionalista y de las J.O.N.S. Números: 971-972-973. 14-17 de mayo de 1944; Diario Ideal en Jaén. Números: 3645-3646-36473648. 12-16 de mayo de 1944. En negrita aparece la palabra: (NO-DO) corresponde a los actos posiblemente exhibidos en las secuencias del noticiario. 


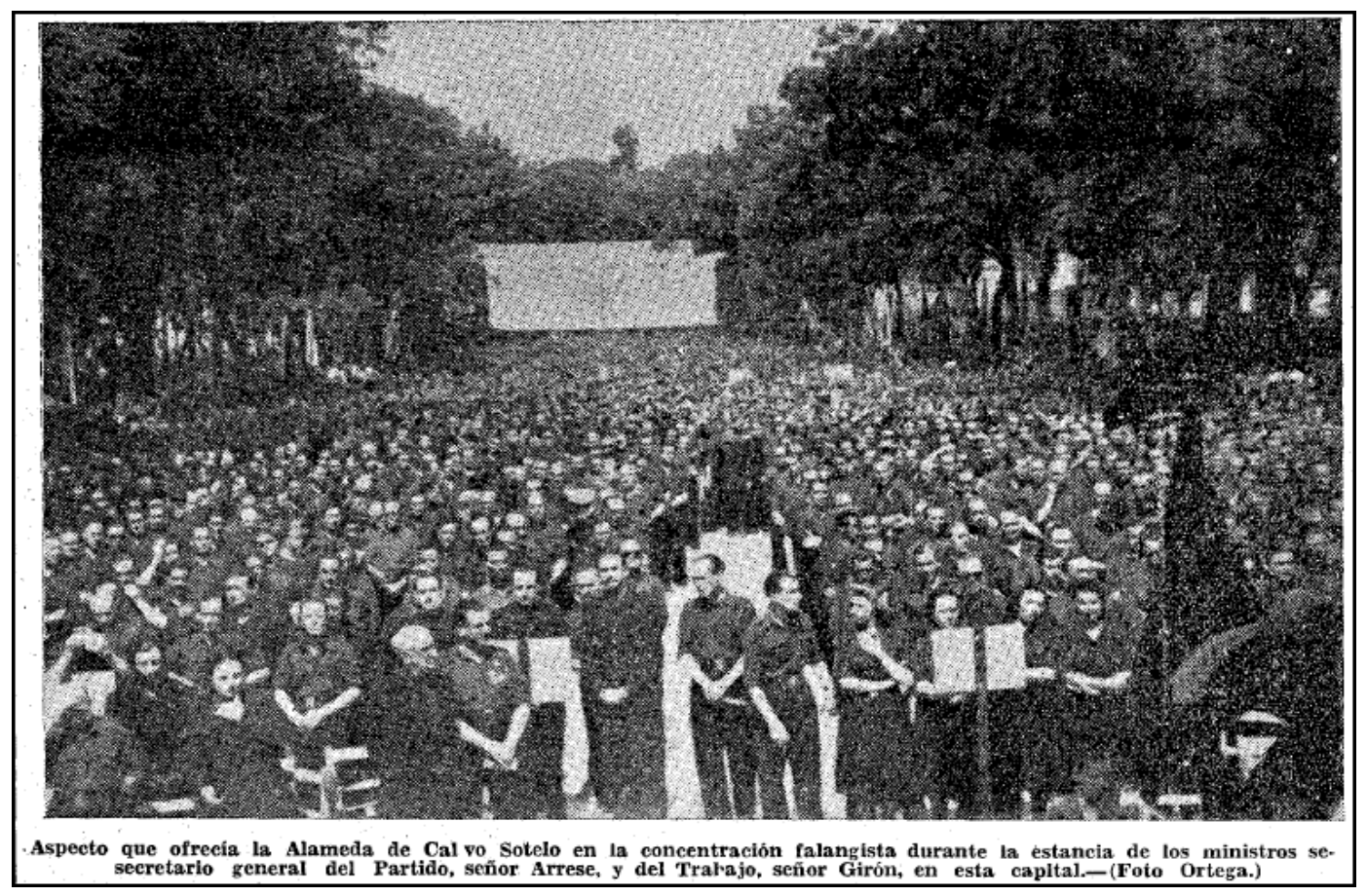

Imagen 4. Acto multitudinario de la falange en la Alameda (1944). Diario Ideal en Jaén.

\begin{tabular}{|l|}
\hline Lunes, 15 de mayo de 1944. Linares \\
\hline 11. 30 h. Recibimiento en el paseo de Linarejos y glorieta de América (NO-DO). \\
\hline Imposición de la medalla de oro a la minería al ministro de trabajo, Girón (NO-DO). \\
\hline Desfile de adhesión (NO-DO). \\
\hline Comisión de Mineros en agradecimiento \\
\hline Visita al Hospital de los Marqueses de Linares \\
\hline Visita a las obras de la colonia-albergue para la recuperación de los obreros \\
\hline 14. 30 Salida para Úbeda. \\
\hline
\end{tabular}

Como podemos intuir, el partido de la falange crea todo un elenco festivo a raíz de la visita de los ministros. En el que todas las instituciones locales y provinciales colaboran en el mayor ornato de las calles o en la construcción de las tribunas, para la presidencia de los ministros en los desfiles, o los arcos triunfales para conmemorar las entradas triunfales en las ciudades. Todo ello con el objetivo de crear una marca reconocible (Durante Asensio, 2014: 75) y asimilarla con la del dictador.

\section{Conclusiones}

Con el presente estudio hemos querido destacar la importancia de las imágenes de la provincia de Jaén en el archivo de "NO-DO" con aspectos cinematográficos ya planteados en otras producciones con características similares. En el que podemos observar notables coincidencias en temas de producción o determinadas formulas para presentar algunos bloques comunes como el desarrollo industrial del olivar.

Unos noticiarios cinematográficos que coinciden en sus primeros años con la desesperada exhibición de la imagen de unidad y progreso del Estado español frente al aislamiento 
internacional y de crisis económica y social que sufre el país. Un Estado dictatorial con unos mecanismos de representación que tiene su máximo valor en la preparación de las visitas triunfales del dictador y sus ministros a la provincia de Jaén, con un partido falangista interesado únicamente en el baño de masas.

Dichas necesidades nos permite comprender la reutilización de secuencias que fueron eliminadas por motivos de montaje o previa censura de la exhibición de su noticiario natural. Postergándose su emisión hasta que son recuperadas las secuencias por los montadores del reportaje para un nuevo carácter simbólico. En dichas imágenes la actualidad de la noticia no importa sino el mensaje que se trata de impartir.

Un análisis del material fílmico que permite recuperar la información visual de reportajes desconocidos como el 74 A, que a través de la documentación textual y fuentes complementarias, nos permiten recomponer parte de los acontecimientos llevados a cabo durante este período histórico.

Incluso dicho estudio de los noticiarios nos permite observar como algunas manifestaciones icónicas locales son absorbidas por las entidades propagandísticas del régimen dictatorial, sobre todo, el de asociar folclore con lo que es genuinamente español y a la vez falangista.

\section{Bibliografía}

ALMANSA MORENO, José Manuel.; MARTÍN ROBLES, Juan Manuel (Dircs.). (2016): 50 años de artes plásticas en Jaén. Creación, medios y espacios (1960-2010). Instituto de Estudios Giennenses. Diputación Provincial de Jaén, p. 553.

CAMARERO RIOJA, Fernando (2013): "El cine educativo de Leandro Navarro (1912-1923)”. En POYATO SÁNCHEZ, Pedro; GÓMEZ GÓMEZ, Agustín (Coords.). Campo y contracampo en el documental rural en España. Diputación de Málaga, Centro de Ediciones de la Diputación de Málaga (CEDMA). Málaga, pp. 13-59.

CAMARERO RIOJA, Fernando (2014): Catálogo de documentales cinematográficos agrarios 1895/1981. Ministerio de Agricultura, Alimentación y Medio Ambiente. Madrid.

COBO ROMERO, Francisco (1994): La guerra civil y la represión franquista en la provincia de Jaén (1936-1950). Diputación Provincial de Jaén, Instituto de Estudios Giennenses. Jaén, pp. 509-510.

COLORADO CASTELLARY, Arturo (2018): Arte, revancha y propaganda. La instrumentalización franquista del patrimonio durante la Segunda Guerra Mundial. Cátedra. Madrid, pp. 117123.

DURANTE ASENSIO, M M Isabel (2014): Retóricas de la nostalgia. Imagen, propaganda e identidad. Los reportajes y documentales del NO-DO en la región de Murcia. Tesis Doctoral. Universidad de Murcia.

HERNÁNDEZ ROBLEDO, Miguel Ángel (2003): Estado e información. El NO-DO al servicio del Estado Unitario (1943-1945). Servicio de Publicaciones de la Universidad Pontificia de Salamanca. Salamanca.

JÓDAR MENA, Manuel (2016): "Imagen proyectada de la provincia de Jaén a través del No-Do". En CAPARRÓS LERA, Josep María; CRUSELLS VALETA, Magí; SÁNCHEZ BARBA, Francesc. (Eds.). Memoria Histórica y cine documental. Comunicaciones del IV Congreso Internacional de Historia y Cine (Barcelona 3-5 septiembre de 2014). Universitat de Barcelona. Barcelona, pp. 156-157.

JURADO ARROYO, Rafael (2003): El cine en Córdoba durante el franquismo. Diputación de Córdoba, Filmoteca de Andalucía. Córdoba.

MENDOZA YUSTA, Rafael (2015-6): "Córdoba y su provincia en los noticiarios NO-DO (19431981)", Arte, arqueología e historia. Núm. 22. Asociación Arte, Arqueología e Historia de Córdoba. Córdoba, pp. 339-349.

NAVARRETE-GALIANO RODRÍGUEZ, Ramón (2003): Huelva en el NO-DO. Fundación el Monte. Sevilla. 
PAZ REBOLLO, María Antonia; SÁNCHEZ ALARCÓN, María Inmaculada (1999): “La historia filmada. Los noticiarios cinematográficos como fuente histórica. Una propuesta metodológica", Filmhistoria online. Vol. IX. Núm. 1. Universidad de Barcelona, pp. 17-33.

RODRÍGUEZ MATEOS, Araceli (2005): "La memoria oficial de la Guerra Civil en No-Do (19431959)", Revista Historia y comunicación social. Núm. 10. Universidad Complutense: Departamento de Historia de la Comunicación Social. Madrid, pp. 179-200.

RODRÍGUEZ MATEOS, Araceli (2008): Un Franquismo de cine. La imagen política del Régimen en el noticiario NO-DO (1943-1959). Ediciones Rialp. Madrid.

ROLL GRANDE, Manuel (2011): "La provincia de Jaén en los documentales del No-Do (19431981)", Códice: revista de investigación histórica y archivística. Año XXVI. Núm. 24. Asociación de Amigos del Archivo Histórico Diocesano de Jaén. Jaén, pp. 85-90.

SÁNCHEZ MARTÍNEZ, José Domingo; JÓDAR MENA, Manuel (2017): “El NO-DO, fijador de miradas y forja de identidad territorial: el caso de la provincia de Jaén". En XXV Congreso de la AGE. 50 años de congresos de geografía. Naturaleza, territorio y ciudad en un mundo global. Asociación de geógrafos españoles. Universidad Autónoma de Madrid, pp. 2245-2254.

TRANCHE, Rafael R; SÁNCHEZ-BIOSCA, Vicente (2006): NO-DO. El tiempo y la memoria. $2^{\mathrm{a}}$ edición. Cátedra. Madrid.

VENTAJAS DOTE, Fernando (2005): "Granada en el NO-DO: Filmaciones en la comarca de Guadix", Boletín del Centro de Estudios Pedro Suárez: Estudios sobre las comarcas de Guadix, Baza y Huéscar. Núm. 18. Centro de Estudios Pedro Suárez. Guadix, pp. 127-172.

VENTAJAS DOTE, Fernando (2006a): Historia del cine en Málaga: los rodajes cinematográficos (1909-2005). Tesis Doctoral. Departamento de Historia Moderna y Contemporánea de la Universidad de Málaga. Málaga. Tomo II, pp. 1113-1170.

VENTAJAS DOTE, Fernando (2006b): "Málaga en el NO-DO (1943-1980)", Isla de Arriarán: revista cultural y científica. Núm. 27. Asociación Cultural Isla de Arriarán. Málaga, pp. 187-221. 